\title{
Nevus of OTA in a Young Woman: a Case Report
}

\author{
Kartika Borra
}

Post Graduate Student, Department of Oral Medicine and Radiology, Sharad Pawar Dental College, DMIMS, Wardha, Maharashtra, India

\begin{abstract}
Nevus of Ota has synonymous names like occulodermalmelanocytosis, congenital ocular melanocytosis, ODM. It is a rare congenital disorder which consists of hyper pigmentation of the facial skin, the eye and mucosae mostly in the region of distribution of trigeminal nerve involvement. The pigmentation may involve the orbital tissue of the affected region. In most case it is unilateral in involvement and in half of the cases intra oral involvement can be seen. Highest cases are recorded in Asian population. $Q$ switched YAG laser surgery can help improve the pigmentation.
\end{abstract}

Keywords: Nevus of Ota, hyperpigmentation, glaucoma, laser surgery

\section{Introduction}

Nevus of Ota is generally a unilateral condition involving ophthalmic and maxillary branches in the region of trigeminal nerve distribution which is followed by mandibular branch in maximum conditions of orofacial pigmentation [1][2]. This entity was first reported by Dr. Ota from Japan in 1939. The nevi usually are present at birth $(60 \%)$ or acquired in condition. Oral mucosal involvement is rarely seen. [3] [4]. Glaucoma is associated with $10 \%$ of individuals. Female predilection is reported in many case studies. Here we present a case of Nevus of Ota with palatal involvement which is rare condition.

\section{Case Report}

A 30-year-old female patient reported to dental OPD with the chief complaint of pain and decayed teeth in the lower right posterior tooth region of jaw since 1 month, and facial pigmentation since childhood. On evaluation of patents history, she had Pain which was continuous and dull aching in nature. There was a decayed tooth in lower right posterior region -2 months. Patient gave no history of itching/irritation or increase in size with pigmentation from childhood. patient was a betel nut chewer and claimed to stop the habit four years ago. Her past medical history was normal.

On extra oral examination (figure 1) there was a Bluish green Hyper pigmentation present on the right side of the face involving first and second branch distribution area of trigeminal nerve. Along with the periocular region on right side (figure 2), right temporal region and forehead. Bluish staining in the sclera of right orbit was also noted. Single right submandibular lymph node was palpable of size $1 \times 0.5$ $\mathrm{cm}$ approximately and was non tender.

Intra oral examination showed bluish pigmentation was present in the mid palatine region (figure 3). A gingival overgrowth present extending from lingual marginal gingiva to interdental region with 45,46 (figure 4). There was Spontaneous and profuse bleeding on probing during examination with lower right molar. Mesial Proximal caries with 46 was noted. A broken tooth piece was seen hanging interdentally between 45 and 46 . The patient was referred to dermatologist and ophthalmologist for consultation about hyper pigmentation of the facial region. Ophthalmic investigation revealed less visual acuity in the right eye but no cataract or glaucoma was diagnosed. Dermatologist confirmed the diagnosis of Ota's nevus. Based on the clinical findings and dermatologist consultation, a diagnosis of nevus of Ota was made.

The possible differential diagnoses for hyperpigmentation in orofacial region include sturge Weber syndrome, facial caféau-lait patchs, nevus spilus, melasma. We conducted an intra oral periapical radiographic examination with 45 and 46 teeth( figure 5). Which revealed grossly decayed coronal portion of 46, with supra eruption of mesial root as the prognosis was poor with the decayed teeth, we have sent the patient for extraction of teeth. However, the patient has been on a regular follow-up. The patient was motivated for the correction of the Nevus with laser therapy, but she was not convinced.

\section{Discussion}

Nevus of Ota (Occulo-dermal melanocytosis) is a benign condition represented as a blue and dark pigmentation, violet or tan spots within the eyes and on the facial skin. The nevus is formed by melanocytes that havenot migrated completely from the neural crest region to the epidermis during the embryonic phase. Consequently, the melanocytes enter the ophthalmic and maxillary branches of the trigeminal nerve region creating spots on the areas supplied. [5]

\section{Epidemiology of Nevus of Ota}

Nevus of Ota is a type of dermal melanocytic hamartoma. It was considered to be quite common in Asians but rare in Caucasian population. Most commonly observed in Japanese women. Very often, nevus of Ota occurs unilaterally in blacks and oriental women (4.8:1). patients may not have any family history for this condition. Nevus of Ota can be seen generally at puberty stage. Feminine sex hormones are suggested as potent stimuli. [6]

\section{Etiological factors}

Stimuli, like infection, trauma, or ultraviolet exposure have been reported to trigger the nevi production. Like sex hormones, these factors are proposed to stimulate the assembly of melanin from amelanotic melanocytes, which further can lead to clinically visible nevi. 
Clinical and Histologic features of Nevus of Ota Blue-black or slate gray macules that are located within the distribution of the primary or second branches of the trigeminal nerve in a unilateral direction of facial skin. Tympanic membrane, nasal, ocular, oral, mucosal surfaces are commonly involved in pigmentation. Diagnosis is based on clinical findings and a biopsy is not needed in majority conditions. Tanino[7] proposed a histological classification of the nevus of Ota in 1939 into five types depending upon the locations of the dermal melanocytes. They are - superficial, superficial dominant, deep dominant, diffuse and deep types. Other authors [8] have classified the nevus of Ota consistent with the distribution of the dermal melanocytes into five types: superficial (type S), superficial dominant (type SD), deep dominant (type DD), diffuse (type Di), anddeep (type De). There are only few reports of palatal pigmentation in patients with nevus of Ota reported in the literature. The detailed examination of ophthalmoscopic and oral region is required for cases of nevus of Ota as increased numbers of melanocytes in hyperpigmented tissues might develop melanoma. Most common ocular complications include increased pressure with or without glaucoma $(10.3 \%)$ which is followed by asymmetric cupping of the optic nervehead that wasn't related to glaucoma $(9.8 \%)$. Less commonly reported finding $\mathrm{s}$ include uveitis $(2.6 \%)$, cataracts $(1 \%)$ orbital melanoma $(0.5 \%)$. Orbital and cerebral melanomas have rarely been related to nevus of Ota. Their occurrence can lead to lethal complications.[9]

\section{Treatment of Nevus of Ota [10]}

1) Camouflage- the utilization of camouflage materials disguises the looks of patients who would haven't any other choice but to live with their deformity.

2) Cryotherapy lightened nevus of Ota by suppressing the function of epidermal melanocytes. (liquid nitrogen $-180 *$ degrees).

3) Dermabrasion can remove epidermal and superficial dermal melanin which may improve the clinical appearance. One study used nitrogen sprays within a range of 5-10 seconds of duration.

4) Laser surgical systems provide high-energy radiation with short pulse durations which allows the selective destruction of the target melanocytes in the region of hyperpigmentation.

\section{Figures}

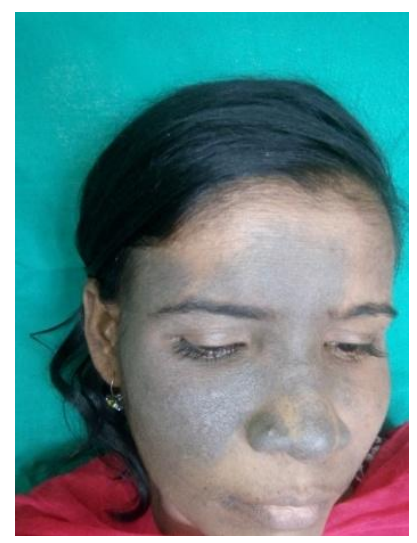

Figure 1: Extra Oral involvement of Nevus of Ota

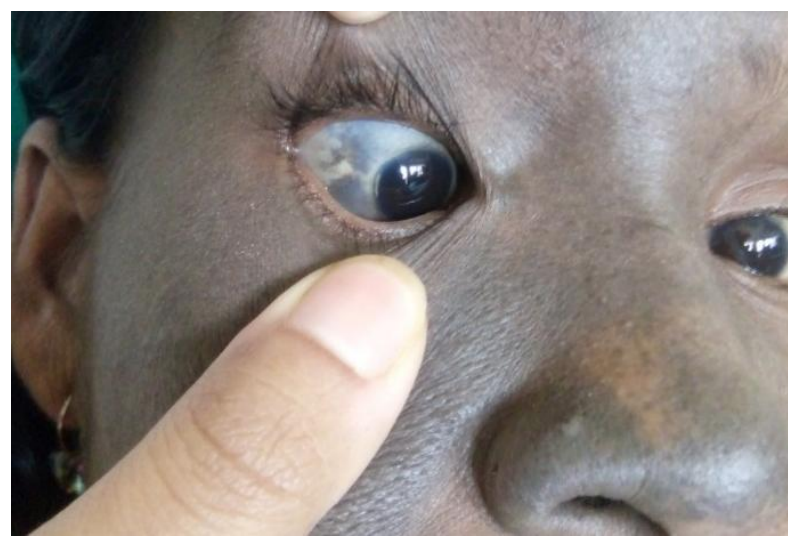

Figure 2: Pigmentation of sclera of left eye

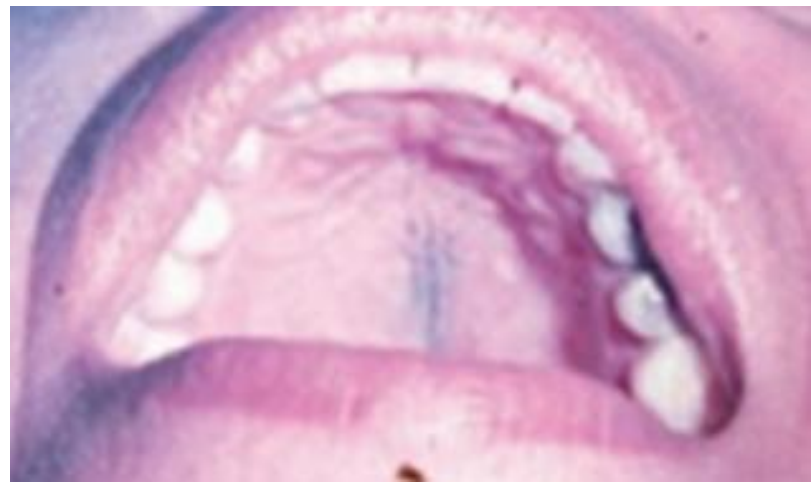

Figure 3: Intra oral pigmentation on hard palate.

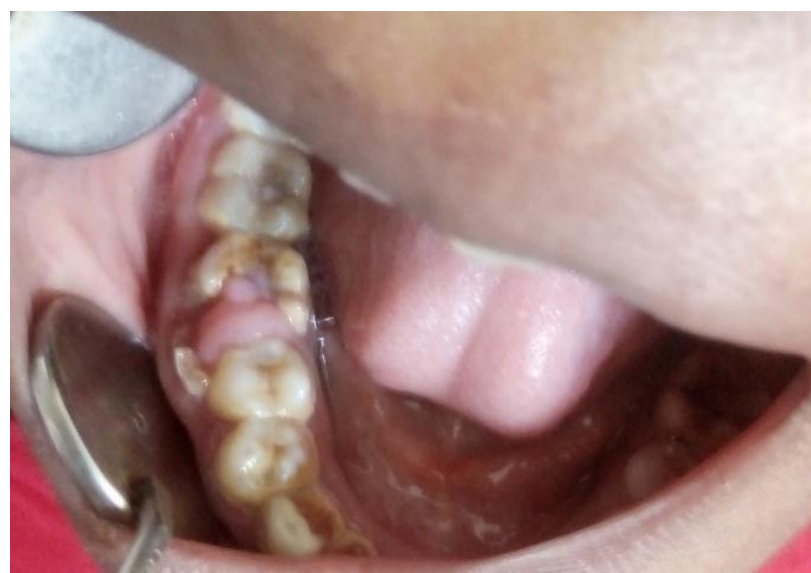

Figure 4: Gingival polyp and decayed teeth with 46

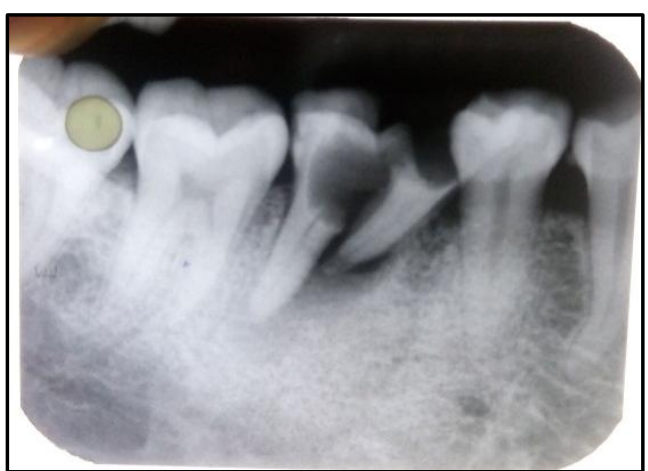

Figure 5: Intra oral peri apical radiograph with 46 shows grossly destructed portion of crown 


\section{Conclusion}

Nevus of Ota is a dermal melanocytic hamartoma that is commonly seen in Asians. Extracutaneous involvement is not uncommon, and should be monitored. The use of laser can effectively clear the nevus, but recurrence is an issue, especially among children. Hence regular follow up is recommended among cases of Nevus of Ota.

\section{References}

[1] Fitzpatrick TB, Kitamura H, Kukita A, Zeller R. Ocular and dermal melanocytosis. AMA Arch Ophthalmol1956;56:830-2.

[2] Patel BC, Egan CA, Lucius RW, Gerwels JW, Mamalis $\mathrm{N}$, Anderson RL. Cutaneous malignant melanoma and oculodermalmelanocytosis (Nevus of Ota): Report of a case and review of the literature. J Am Acad Dermatol 1998;38(5 Pt 2):862-5.

[3] Ota M. Nevus fuscoceruleusophthalmomaxillaris. Tokyo Med J 1939; 63:1243-5.

[4] Wilcox JC. Melanamatosis of skin and central nervous system. Am J Dis Child 1939; 57:391.

[5] Solanki J, Gupta S, Sharma N, Singh M, Bhateja S. Nevus of ota"- a rare pigmentation disorder with intraoral findings. J Clin Diagn Res. 2014;8(8):ZD49ZD50. doi:10.7860/JCDR/2014/9978.4772

[6] Mohan RP, Verma S, Singh AK, Singh U. 'Nevi of Ota: the unusual birthmarks': a case review. BMJ Case Rep. 2013;2013:bcr2013008648.

[7] Tanino H. Übereine in Japan haufigvorkom-mende Navusform:

"Naevusfusco-caeruleus ophthalmomaxillaris Ota", I. Mitteilung: Beobachtungüber Lokalisation, Verfärbung, Anordnung and histologische Veränderung. Jpn J Dermatol.1939; 46:435-51.

[8] Chan HH, Lam LK, Wong DS, Leung RS, Ying SY, Lai $\mathrm{CF}$, et al. Nevus of Ota: a new classification based on the response to laser treatment. Lasers Surg Med. 2001;28(3):267-72.

[9] Sebastião Cronemberger, Nassim Calixto, Henrique Leite Freitas;Nevus of Ota: clinical-ophthalmological findings; Rev Bras Oftalmol. 2011; 70 (5): 278-83

[10] Henry H.L. Chan, MB, FRCPG, FRCPE, Taro Kono, MD,Skinmed. 2003;2(2). 